\title{
Age, Gender Pattern and Liver Function Markers in Hepatitis B and C Seropositive Participants Attending a Health Facility in Yaba-Lagos, Nigeria
}

\author{
Toyosi Raheem1, Mercy Orukpe-Moses1,2, Samuel Akindele1, Maureen Wahab', \\ Oluranti Ojerinola ${ }^{1}$, David Akande ${ }^{1}$, Isamaila Ahmed Ochacha ${ }^{1}$, Maureen Aniedobe ${ }^{1}$ \\ ${ }^{1}$ Clinical Diagnostic Laboratory, Nigerian Institute of Medical Research Yaba, Lagos, Nigeria \\ ${ }^{2}$ National Youth service Corps, Lagos, Nigeria \\ Email: toyosiraheem55@gmail.com
}

How to cite this paper: Raheem, T., Orukpe-Moses, M., Akindele, S., Wahab, M., Ojerinola, O., Akande, D., Ochacha, I.A. and Aniedobe, M. (2021) Age, Gender Pattern and Liver Function Markers in Hepatitis B and C Seropositive Participants Attending a Health Facility in Yaba-Lagos, Nigeria. Journal of Biosciences and Medicines, 9, 44-58.

https://doi.org/10.4236/jbm.2021.97007

Received: June 2, 2021

Accepted: July 12, 2021

Published: July 15, 2021

Copyright $\odot 2021$ by author(s) and Scientific Research Publishing Inc. This work is licensed under the Creative Commons Attribution International License (CC BY 4.0).

http://creativecommons.org/licenses/by/4.0/ (c) (i) Open Access

\begin{abstract}
Background: Individuals with sero-positivity for Hepatitis B and C have been reported. Most seropositive individuals appear healthy. Liver function markers such as AST, ALT, ALP, Bilirubin and total protein levels are markers for assessing liver impairment. This study (i)assessed seroprevalence of HBV, HCV and both HBV and HCV (ii) HBV and or HCV seropositivity and age or gender, (iii) assess gender and liver function markers and (iv) update data on liver function and simple diagnostic markers. Materials and Methods: This was a prospective, cross sectional study of asymptomatic individuals presenting at the Clinical Diagnostic Laboratory of Nigerian Institute of Medical Research (NIMR), Yaba, Lagos, Nigeria from January 2018 to August 2020. Markers of liver function were investigated on hepatitis B and or C sero-positive and negative participants using TC Matrix Chemistry analyser (Teco Diagnostics, USA) and Biobase reagent Kits. Data were analyzed using descriptive and inferential statistics. Results: Out of 475 participants, $60.4 \%$ were males and $39.6 \%$ females. $53 \%$ of males and $32.5 \%$ of females were sero-positive for $\mathrm{HBV}$ while $32.5 \%$ of males and $14.5 \%$ of females were sero-positive for HCV. 75.3\% and 76.1\% of Age group 20 - 40 years were sero-positive for Hepatitis B and C respectively. Mean AST levels of $17.49 \pm$ $13.69,33.46 \pm 93.42$ and $19.82 \pm 12.54$ respectively among those sero-positive for HBV, HCV, and both HBV and HCV. Mean ALT levels of $17.68 \pm 14.32$, $40.26 \pm 13.86$ and $20.04 \pm 12.78$ respectively for HBV, HCV and both HBV and HCV sero-positive cases. Mean ALP levels were $77.52 \pm 34.0$ for HBV sero-positive cases, $82.04 \pm 38.45$ in HCV and $77.95 \pm 30.48$ in both HBV and HCV sero-positive cases. Mean Total Bilirubin levels of HBV, HCV and both
\end{abstract}


HBV and HCV sero-positive cases were $13.25 \pm 14.52,14.98 \pm 20.74,10.58 \pm$ 4.91 respectively while Mean Total protein levels were $77.24 \pm 6.27$ in HBV, $77.87 \pm 5.56$ in $\mathrm{HCV}$ and $77.0 \pm 5.99$ in both $\mathrm{HBV}$ and HCV sero-positive cases. ALP, bilirubin and total protein were all within normal reference values in $\mathrm{HBV}, \mathrm{HCV}$ and $\mathrm{HBV} / \mathrm{HCV}$ dual infections. AST and ALT values were significantly elevated in $\mathrm{HCV}$ seropositivity compared to $\mathrm{HBV}$ single and $\mathrm{HBV} / \mathrm{BCV}$ dual seropositivity. Conclusion: $30 \%$ prevalence of $\mathrm{HBV}, \mathrm{HCV}$ and both HBV and HCV were observed. Age 20 - 40 years was significantly higher in seropositivity for hepatitis $\mathrm{B}, \mathrm{C}$ and $\mathrm{B}$ and $\mathrm{C}$ dual seropositivity. More males than females showed seropositivity for hepatitis B and C. There was no significant difference between gender and liver function markers. AST and ALT remain reliable markers of liver function.

\section{Keywords}

Hepatitis, Liver Function Tests, Parameters, Infection

\section{Introduction}

The Liver is the main internal organ, weighing about 1200 - $1500 \mathrm{~g}$. This has more functions than any other organ, and it can support life even though only $10 \%-20 \%$ of the liver tissue is functioning. The significant role of the liver includes purification, synthesis of proteins and cholesterol; inactivation of hormones and the regulation of the amount of testosterone in the blood; and storage of sugars, fats and vitamins. There are several causes for liver inflammation, such as toxin, biochemical, bacterial, pharmacology, or immune-mediate attack on liver. For non-specific symptoms or screening purposes, usually LFT is performed [1] [2].

Infections of chronic hepatitis $B$ virus (HBV) and hepatitis $\mathrm{C}$ virus (HCV) are significant public health issues worldwide. An estimated two billion people worldwide have evidence of past or current $\mathrm{HBV}$ infection, and 350 million are chronic HBV surface antigen carriers (HBsAg) [1]. Age-specific HBsAg seroprevalence varies greatly by geographic area, with the highest prevalence $(>5 \%)$ in Sub-Saharan Africa (SSA), East Asia, parts of the Balkan region, Pacific Islands, and South America's Amazon Basin. In regions such as Central America, North America and Western Europe, incidence is below 2\% [1]. Over 50 million people in Africa are chronically infected, with a mortality risk of around $25 \%$.

In Sub-Saharan Africa, carrier rates of the virus range from $9 \%-20 \%$ [3]. Nigeria has been documented as highly endemic to HBV infection and about 75 percent of its population are likely to have been exposed to the virus at one time or another in their lives and about 18 million Nigerians were infected [4]. Port Harcourt registered a prevalence rate of $4.3 \%$ [5]; Ilorin 5.7\% [6], Maiduguri $11.6 \%$ [7] and Zaria $8.3 \%$ [8]. A seroprevalence of $23.3 \%$ among patients attending all clinics at the Aminu Kano Teaching Hospital (AKTH) had been reported [9]. A recent systematic analysis reported that 170 million people [10] 
had a history of HCV infection (i.e. positive HCV-antibody) and 80 million had chronic viraemic infection [11]. The prevalence of Sub-Saharan Africa is moderate $(1.5 \%-3.5 \%)$ and Nigeria is $1.1 \%$ [11].

Dual HBV and HCV infection in the same host varies from $9 \%-30 \%$, depending on the geographical area [10]. These numbers can underestimate the true number of people with $\mathrm{HBV} / \mathrm{HCV}$ co-infection since there is a well-known entity of occult $\mathrm{HBV}$ infection (i.e., patients with negative hepatitis B surface antigen (HBsAg) but detectable serum HBV DNA) in patients with chronic hepatitis C [10]. The estimated global prevalence of co-infection with $\mathrm{HBV} / \mathrm{HCV}$ in HBsAg positive patients is approximately $5 \%-20 \%$ and in HCV positive patients is $2 \%-10 \%$.

The HBV/HCV co-infected patients have higher rates of cirrhosis ( $44 \%$ vs. $21 \%$ ) and decompensated liver disease ( $24 \%$ vs. $6 \%$ ) compared to HBV mono-infected patients. Similarly, HBV/HCV co-infected patients have a higher incidence of cirrhosis (95\% vs. $49 \%$ ) and more severe decompensated liver disease (Child-Pugh class C 37\% vs. 0\%) compared with HCV mono-infected patients [12].

Epidemiological research has long indicated an increased risk of hepatocellular carcinoma (HCC) in patients with dual HBV/HCV infection and evidence indicates that HBV may trigger neoplastic cycle, while HCV may serve as a promoter, and that the two conditions could be synergistic in contributing to the growth of hepatocellular carcinoma (HCC) [13].

The different functions of the liver are expressed by liver function markers. Bilirubin, total protein, albumin, globulin, alkaline phosphatase (ALP), gamma glutamyl, transaminase alanine (ALT), and transaminase aspartate (AST) are generally included. Abnormality in liver function markers provides an idea of the liver function and its enzymes are usually elevated in hepatic abnormality with alanine aminotransferase (ALT) more specific to the liver [14].

Liver disease constitutes a significant health burden and viral infections are responsible for significant numbers of liver diseases. Most common of these are HBV and HCV infection [15].

\section{Hepatitis B Infection}

Hepatitis B virus is an enveloped DNA virus, and a member of the family Hepadnaviridae hepatotropic DNA viruses. Hepatitis B virus transmission results from an exposure to infected blood or body fluids. Possible forms of transmission include, but are not limited to, unsafe sexual blood transfusions, reuse of infected needles and syringes, and vertical mother-to-child transmission during childbirth. Without action, a mother who is positive for $\mathrm{HBsAg}$ is at $20 \%$ risk of passing the infection to her offspring at the time of birth.

If the mother is also positive for HBeAg (Hepatitis B envelope antigen), this risk is as high as 90 per cent. The HBV infection can be transmitted within households between family members, likely through contact with non-intact skin or mucous membrane with HBV-containing secretions or saliva [16]. Nonetheless, an established risk factor cannot be associated with at least 30 per cent 
of identified adult hepatitis B [17]. Transmission trends are different in many developed countries (e.g. those in Western Europe and North America) from the ones described above. Currently, most diseases in these countries are spread through sexual activity and the injection of drug use during young adulthood. $\mathrm{HBV}$ is a major occupational hazard contagious to health care staff [18]. HBV is not transmitted by infected food or water, and cannot be easily distributed in the workplace. The normal incubation period for the virus is 90 days but can range from around 30 to 180 days [19]. HBV can be detected within 30 to 60 days of infection and persists for widely variable periods.

Hepatitis infection could be acute or chronic. Initial phases of this infection stage are characterized by the presence of HBsAg, elevated serum HBV DNA, $\mathrm{HBeAg}$, and normal serum aminotransferase (ALT) levels, and minimal or negligible inflammation of the liver biopsy [20].

Chronic infection occurs as an early stage progression of the acute HBV infection due to the failure of the host to mount the requisite immune stimulus to ensure complete viral clearance and consequent disease resolution. This is serologically characterized by relative increase in anti-HBcAg IgG serum, absence or lower anti-HBsAg IgG titers, and either mild or severe damage to the liver as shown by ultrasonography [18]. This stage of the disease can also be characterized by normal or elevated levels of serum transaminases (aspartate transaminase (AST) and alanine transaminase (ALT)) and other hepatic integrity markers [19].

HBeAg's serological presence is constant at all phases of the infection. The presence of this antigen in combination with increased viral load (HBV DNA > $10^{3}$ copies $/ \mathrm{ml}$ ) and higher ALT (>60 IU/l) is a clear indicator of viral infection, replication and infectivity [18]. Patients suffering from these symptoms are placed on retroviral. HBeAg seroconversion is a central occurrence in the natural history of $\mathrm{HBeAg}$-positive $\mathrm{CHB}$ patients [21]. Seroconversion of $\mathrm{HBeAg}$ to $\mathrm{HBeAb}$ is believed to be accompanied by cessation of HBV replication and hepatic remission. Several studies have shown that seroconversion with a marked reduction in HBV replication in the majority of patients is correlated with biochemical and histological remission of inflammatory activity [22].

\section{Hepatitis C Infection}

HCV infection varies in their distribution in different parts of the world. There are four primary transmission routes: health-associated transmission, drug-injection, mother-to-child transmission (MTCT), and sexual transmission. In low- and middle-income countries, HCV infection is most generally associated with unsafe injection procedures, and invasive procedures with insufficient infection management measures such as renal dialysis and unscreened (or inadequately screened) blood transfusions in health care facilities [23]. Persons who received untested blood products prior to the implementation of HCV blood screening in (high income countries) are also at risk, and reports from the WHO indicate that 39 countries still do not regularly screen blood transfusions 
for blood-borne viruses [23]. Most HCV infections occur among people in middle- and high-income countries, especially among those who use unsterile equipment to inject drugs. People who inject drugs have a high global infection prevalence of around 67\% [24]. Of the estimated 16 million people who actively inject drugs in 148 countries, 10 million have serological evidence for HCV infection [24]. There is a moderate risk of HCV MTCT that is higher in mothers with HIV co-infection (10\% - 20\%) [25]. The risk of HCV sexually transmitted is also higher in HIV-positive individuals, particularly homosexuals [26], but is low among HIV-uninfected heterosexual couples [27]. Certain routes of blood-borne transmission include health-care staff acquisition, cosmetic procedures (such as tattooing and body piercing), scarification and circumcision [28] and intranasal drug usage.

The hepatitis $\mathrm{C}$ virus induces both chronic and acute infections. Acute HCV infection is defined as the presence of certain HCV infection markers within six months of HCV exposure and infection, and is characterized by the appearance of HCV RNA, HCV core antigen (p22 Ag), and subsequently HCV antibodies which may or may not be associated with viral clearance. HCV antibodies develop as an integral part of an acute infection and persist throughout life. Acute infection is typically clinically silent, and is associated only very rarely with life-threatening illness. Spontaneous clearance of acute HCV infection usually occurs in $15 \%-45 \%$ of infected individuals in the absence of treatment within six months of infection, but this varies by area and population [29]. Nearly all other $55 \%-85 \%$ of people who do not clear up HCV within six months are identified as having chronic HCV infection. Chronic HCV infection if left untreated, can lead to liver cirrhosis, liver failure and HCC. Of those with chronic HCV infection, the chance of liver cirrhosis within 20 years is $15 \%-30 \%$ [30]. The chance of hepatocellular carcinoma in people with cirrhosis is around 2 $4 \%$ per annum and infection clearance, whether spontaneous or as a result of antiviral therapy, does not offer a lasting defense against reinfection [31].

\section{Materials and Method}

Study Area, Period, and Design This is a retrospective, cross-sectional study conducted from January 2018 to August 2020 at the Nigerian Institute of Medical Research Yaba, Lagos State, Nigeria. A total of 475 patients who attended the Clinical Diagnostic Laboratory, NIMR were enrolled in the study.

Study Population; The study population included all the patients who tested positive for HBV, HCV and HBV and HCV co-infection. Patients who were negative for both types of hepatitis served as negative control. Structure questionnaires were administered to capture socio-demographic variables such as age, sex, religion, ethnicity, marital status, profession and work experience.

Blood sampling; Five ml whole blood samples were collected from participants under aseptic conditions after obtaining their informed consent. The blood sample was divided into two parts: one part was transferred to a tube with Ethylenediamine tetra acetic acid (EDTA), while the other part was transferred 
to a plain tube and left undisturbed for 30 - 60 minutes. Serum was then collected after centrifugation of the blood and immediately stored at $-20^{\circ} \mathrm{C}$ until analysed.

Hepatic studies and serological tests for HBV and HCV: Markers of liver function assessed for all participants in the study. These were aspartate aminotransferase (AST), alanine aminotransferase (ALT), alkaline phosphatase (ALP), total bilirubin, direct bilirubin, total protein and albumin concentrations. Markers of liver function were assayed using automatic blood chemistry analyzer (TC MATRIX Automated Chemistry Analyzer, USA). HBsAg and anti-HCV antibodies were determined using rapid diagnostic kits (LabAcon and Triple H Rapid Test Kits) as described by the manufacturers. For Hepatitis B, about $100 \mu \mathrm{L}$ blood was placed on test cassette using micropipette. The results were recorded after $20 \mathrm{~min}$. The presence of two red lines at both the test and the control bands were reported as positive results. The presence of only one line at the control band was reported as sero-negative results. For Hepatitis C, about $10 \mu \mathrm{L}$ blood was placed on sample area of the cassette using micropipette and four drops of assay diluent were added. The result was recorded after $5-20 \mathrm{~min}$. The presence of two red lines at both the test and control bands were reported as sero-positive results while those with one red line at the control band only were reported as sero-negative results.

Statistical analysis: Data analysis was performed using SPSS version 20. The Student $\mathrm{t}$ test was used for comparison between seropositive and control groups. The results were considered to be statistically significant when $\mathrm{p}$ values were $<0.05$ using Chi-square test.

Ethical Considerations: Informed consent was obtained from participants. Unique identifiers were used for participants' samples and assay results to prevent identification by unauthorized person (s) and maintain confidentiality of participants' information.

\section{Results}

A total of 475 cases of Hepatitis B and Hepatitis C were included in this study, with $287(60.4 \%)$ males and 188 (39.6\%) females. $141(30.0 \%)$ and $334(70.0 \%)$ were sero-positive and negative respectively (Table 1). Out of 141 positive cases, $73(51.8 \%)$ were sero-positive for hepatitis B while 46 (32.6\%) were seropositive for hepatitis C and 22 (15.6\%) were sero positive for both HBV and HCV (Table 2 ). Gender and seropositivity showed $53 \%, 32.5 \%$, and $14.5 \%$ were seropositive for $\mathrm{HBV}, \mathrm{HCV}$, and both $\mathrm{HB}$ and $\mathrm{C}$ respectively among males while 50\%, 32.8\% and $17.2 \%$ were seropositive for $\mathrm{HBV}, \mathrm{HCV}$, and both $\mathrm{HB}$ and $\mathrm{C}$ respectively among female participants (Table 3 ) The study showed a total of $55(74.3 \%)$ participants were within age range of 20 - 40 years; 15 (20.3\%) were 41 - 60 years and $4(5.4 \%)$ were above 61 years (Table 4$)$. For HCV sero-positivity, $35(76.1 \%)$ were 20 - 40 years, $10(21.7 \%)$ were 41 - 60 years and 1 (2.2\%) was above 61 years. For sero-positivity to HBV and HCV, 18 (85.7\%) were 20 - 40, 3 (14.3\%) were 41 - 60 years (Table 4 ). 
Table 1. Distribution of Hepatitis sero-positive and sero-negative among participants ( $n$ $=475)$.

\begin{tabular}{cc}
\hline Test name & Number of patients (\%) \\
\hline Hepatitis positive & $141(30.0)$ \\
Hepatitis negative & $334(70.0)$ \\
Total & $475(100)$ \\
\hline
\end{tabular}

Table 2. Distribution of the serotypes among the hepatitis positive participants $(n=141)$.

\begin{tabular}{cc}
\hline & No. of participants (\%) \\
\hline Hepatitis B seropositive & $\mathbf{7 3 ( 5 1 . 8 )}$ \\
Hepatitis C seropositive & $46(32.6)$ \\
Hepatitis B and C seropositive & $22(15.5)$ \\
Total & $141(100.0)$ \\
\hline
\end{tabular}

Table 3. Hepatitis B, C and both B \& C sero-positive in male and female participants (\%) $(n=141)$.

\begin{tabular}{cccc}
\hline Test name & \multicolumn{2}{c}{ Number of cases $(\%)$} & \\
\hline & Male & Female & Total \\
\hline HBV & $44(53)$ & $29(50)$ & 73 \\
HCV & $27(32.5)$ & $19(32.8)$ & 46 \\
Both HBV and HCV & $12(14.5)$ & $10(17.2)$ & 22 \\
Total & $\mathbf{8 3 ( 1 0 0 )}$ & $\mathbf{5 8 ( 1 0 0 )}$ & $\mathbf{1 4 1}$ \\
\hline
\end{tabular}

Table 4. Age and HBV, HCV and both HBC and HCV sero-positivity \& percentage ( $n=$ 141).

\begin{tabular}{ccccc}
\hline & \multicolumn{4}{c}{ Number of cases (\%) } \\
\hline Age of patients & HBV & HCV & Both HBV and HCV & Total \\
\hline $20-40$ years & $55(74.3)$ & $35(76.1)$ & $18(85.7)$ & 108 \\
$41-60$ years & $14(20.3)$ & $10(21.7)$ & $4(14.3)$ & 28 \\
Above 61 years & $4(5.4)$ & $1(2.2)$ & $0(0)$ & 5 \\
Total & $73(100)$ & $46(100)$ & $22(100)$ & 141 \\
\hline
\end{tabular}

Those 40 years and below showed significant difference in level of conjugated bilirubin than those sixty years and above $[\mathrm{p}=0.039]$ (Table 5). However, no significant difference in levels of liver function markers in those seropositive for hepatitis B, C or both seropositivity in those 40 years and those above 40 years.

There was no significant difference between age and levels of liver function markers ( $\mathrm{p}>0.05$ ) (Table 6). Also, except for conjugated and unconjugated bilirubin levels in hepatitis B, and both B and C seropositivity, there was no significant difference $(\mathrm{p}>0.05)$ in hepatitis $\mathrm{B}$ and $\mathrm{C}$ dual seropositivity and liver function markers. However, in hepatitis $\mathrm{C}$ seropositive participants, AST and ALT levels were significantly elevated than in the negative participants $[p=0.009]$ (Table 7). 
Table 5. The mean value of biochemical markers of Liver Function, Gender distribution in Hepatitis positive (HBV, HCV, both $\mathrm{HBV}$ and $\mathrm{HCV})$ participants $(n=141)$.

\begin{tabular}{ccccc}
\hline Parameters & Males & Females & F & p-value \\
\hline Aspartate Transaminase (AST) & 19.15 & 18.40 & 0.323 & 0.570 \\
Alanine Transaminase (ALT) & 21.79 & 19.41 & 0.629 & 0.428 \\
Alkaline Phosphatase (ALP) & 79.56 & 77.29 & 2.220 & 0.137 \\
Total Bilirubin (TB) & 14.72 & 16.11 & 1.010 & 0.316 \\
Conjugated Bilirubin (CB) & 6.47 & 5.09 & 0.830 & 0.363 \\
Unconjugated Bilirubin (UB) & 8.68 & 7.83 & 0.656 & 0.419 \\
Total protein (TP) & 76.74 & 77.15 & 3.764 & 0.050 \\
Albumin (ALB) & 44.05 & 44.93 & 0.045 & 0.831 \\
Globulin (GLB) & 32.61 & 33.59 & 3.310 & 0.070 \\
\hline
\end{tabular}

Table 6. The mean value of biochemical markers of Liver Function and Age distribution in Hepatitis seropositive participants (HBV, HCV, both HBV and HCV) $(n=141)$.

\begin{tabular}{|c|c|c|c|c|c|}
\hline Parameters & $20-40$ Years & $41-60$ Years & Above 60 Years & $\mathrm{F}$ & p-value \\
\hline Aspartate Transaminase (AST) & 19.36 & 16.56 & 24.75 & 0.294 & 0.746 \\
\hline Alanine Transaminase (ALT) & 21.89 & 18.05 & 19.08 & 0.162 & 0.851 \\
\hline Alkaline Phosphatase (ALP) & 80.21 & 72.83 & 88.50 & 2.007 & 0.136 \\
\hline Total Bilirubin (TB) & 15.51 & 13.68 & 22.40 & 0.496 & 0.609 \\
\hline Conjugated Bilirubin (CB) & 5.70 & 5.03 & 16.23 & 3.270 & 0.039 \\
\hline Unconjugated Bilirubin (UB) & 8.55 & 8.04 & 6.09 & 0.424 & 0.655 \\
\hline Total Protein (TP) & 77.04 & 76.53 & 77.00 & 0.150 & 0.861 \\
\hline Albumin (ALB) & 44.52 & 44.29 & 42.91 & 0.967 & 0.381 \\
\hline Globulin (GLB) & 32.73 & 33.67 & 34.08 & 0.952 & 0.387 \\
\hline
\end{tabular}

Table 7. Mean value of biochemical markers of Liver Function in Hepatitis seropositive participants (HBV, HCV, both $\mathrm{HBC}$ and $\mathrm{HCV}$ ).

\begin{tabular}{|c|c|c|c|c|}
\hline \multirow[b]{2}{*}{$\begin{array}{l}\text { Biochemical } \\
\text { parameters }\end{array}$} & \multicolumn{3}{|c|}{ Group hepatitis participants } & \multirow[t]{2}{*}{ Normal value } \\
\hline & $\begin{array}{c}\text { HBV } \\
(n=73)\end{array}$ & $\begin{array}{c}\text { HCV } \\
(n=46)\end{array}$ & $\begin{array}{l}\text { Both HBV and HCV } \\
\qquad(\mathrm{n}=22)\end{array}$ & \\
\hline AST & 17.49 & 33.46 & 19.82 & $0-12 \mathrm{iu} / \mathrm{ml}$ \\
\hline ALT & 17.68 & 40.26 & 20.04 & $0-12 \mathrm{iu} / \mathrm{ml}$ \\
\hline ALP & 77.52 & 82.04 & 77.95 & $60-170 \mathrm{iu} / \mathrm{ml}$ \\
\hline $\mathrm{TB}$ & 13.25 & 14.98 & 10.58 & $\leq 17.0 \mathrm{umol} / \mathrm{L}$ \\
\hline $\mathrm{CB}$ & 4.06 & 6.08 & 3.26 & $\leq 4.3 \mathrm{umol} / \mathrm{L}$ \\
\hline UB & 9.15 & 10.02 & 7.36 & $\leq 12.7 \mathrm{umol} / \mathrm{L}$ \\
\hline $\mathrm{TP}$ & 77.24 & 77.87 & 77.00 & $64-83 \mathrm{~g} / \mathrm{L}$ \\
\hline ALB & 43.79 & 44.10 & 44.50 & $38-48 \mathrm{~g} / \mathrm{L}$ \\
\hline GLB & 33.58 & 33.52 & 32.50 & $26-40 \mathrm{~g} / \mathrm{L}$ \\
\hline
\end{tabular}


Table 1 showed that out of the total 475 participants, 30\% were seropositive while $70 \%$ were seronegative for hepatitis $\mathrm{B}, \mathrm{C}$ and both $\mathrm{B}$ and $\mathrm{C}$.

Table 2 showed hepatitis B, C and both B and C sero prevalence of $51.8 \%$, $32.6 \%$ and $15.5 \%$ respectively in the 141 seropositive participants.

Distribution of positive cases in Hepatitis among gender indicated that 44 (53\%) males were positive to HBV, 27 (32.5\%) males were positive to HCV and $12(14.5 \%)$ males were positive to both HBV and HCV. Positive cases among females indicated 29 (50\%) females were positive to HBV, 19 (32.8\%) females were positive to $\mathrm{HCV}$ and $10(17.2 \%)$ females were positive to both $\mathrm{HBV}$ and HCV (Table 3).

Age group 20 - 40 years had $74.3 \%$ hepatitis B seropositivity, 76.1\% hepatitis C seropositivity, while $85.7 \%$ had both hepatitis B and C seropositivity. Participants with age group 41 - 60 years had $20.3 \%, 21.7 \%$ and $14.3 \%$ for hepatitis B, C and both B \& C seropositivity respectively as shown in (Table 4).

Table 5 showed no significant difference between hepatitis B and C seropositivity and liver function markers in both male and female.

Table 6 showed that only conjugated bilirubin showed significant difference between liver function markers and age in both male and female participants ( $\mathrm{p}$ $=0.039$ ). There was no significant difference between other liver function markers and age in both male and female HBV, HCV and both B and C dual seropositive participants ( $\mathrm{p}>$ than 0.05 ).

Table 7 showed significantly elevated AST and ALT liver function markers in hepatitis C seropositivity ( $\mathrm{p}=0.009$ ). The mean AST levels of HBV, HCV, and both HBV and HCV were $17.49 \pm 13.69,33.46 \pm 93.42,19.82 \pm 12.54$ respectively. The mean ALT levels were $17.68 \pm 14.32$ in HBV, 40.26 \pm 136.86 in HCV and $20.04 \pm 12.78$ in both HBV and HCV. For mean ALP levels, $77.52 \pm 34.00$ in $\mathrm{HBV}, 82.04 \pm 38.45$ in $\mathrm{HCV}$ and $77.95 \pm 30.48$ in both HBV and HCV. The mean Total Bilirubin levels of HBV, HCV and both HBV and HCV were $13.25 \pm$ $14.52,14.98 \pm 20.74,10.58 \pm 4.91$ respectively. Mean Total protein levels were $77.24 \pm 6.27$ in HBV, $77.87 \pm 5.56$ in $\mathrm{HCV}$ and $77.00 \pm 5.99$ in both $\mathrm{HBV}$ and HCV (Table 7).

\section{Discussion}

Infections of hepatitis $\mathrm{B}$ and $\mathrm{C}$ are prevalent from region to region and from one population to another in a country or region in various parts of the world [32]. According to our study, the prevalence of HBV, HCV, and both HBV and HCV were $51.8 \%, 32.6 \%$ and $15.6 \%$ respectively. Our study appeared to be similar to that of [15] where a prevalence of $\mathrm{HBV}, \mathrm{HCV}$, and $\mathrm{HBV}$ and $\mathrm{HCV}$ dual positivity of $75 \%, 23 \%$, and $2 \%$, respectively were reported. However, the $2 \%$ seropositivity for HBV and HCV dual sero status was far lower than the $15.6 \%$ in our study. The reason for this could be due to differences in the geographical locations of the different studies. Though the prevalence of hepatitis seropositivity in this study was high, we are of the opinion that the high prevalence could be due to being a health facility-based study. 
The finding of seroprevalence of 51.8\% was recorded for $\mathrm{HBV}$ and $32.6 \%$ for $\mathrm{HCV}$ in this study showed that HBV, HCV are both endemic in the study location. WHO in 2010, defined low prevalence of hepatitis to be $<2 \%$, moderate prevalence as $2 \%-8 \%$, and high prevalence as $>8 \%$ HBsAg positivity.

Our study shows that among HBV, males were $53 \%$ and females were $50 \%$, among HCV males were $32.5 \%$ and females were $32.8 \%$ while among both HBV and HCV males and females were $14.5 \%$ and $17.2 \%$, respectively, which is comparable to the study of [33] [34]. A previous study reported significant association between age and HBV and HCV seropositivity in Abeokuta, Nigeria [35]. Our study showed that both $\mathrm{HBV}$ and $\mathrm{HCV}$ co-infection rates were highest among individuals in the age group of $20-40$ (85.7\%), followed by the age group of 41 - 60 years $(14.3 \%)$, which was similar to a previously published study in the United States [44]. A higher prevalence in the 20 - 40 years age group may be associated with increased exposure to risk factors for $\mathrm{HBV} / \mathrm{HCV}$ co-infection. Our present study supports this report because higher HBV and HCV prevalence was found among age group 20 - 40 years than in other age groups. Age of peak infection in this study is in consonance with reports from previous studies [35] [36]. The socio-economic implication of this finding more in the age group 20 - 40 years is imperative. This age group is economically and sexually active age group. The possibility of higher spread of HBV and HCV in this age group via sexual activities and reduction of productivity due to liver dysfunction is high. More males were $\mathrm{HBV} / \mathrm{HCV}$ sero-positive compared to females. This finding agreed with the reports of [37] [38] [39] done in Nigeria and also agrees with the earlier reports of [40] from Southeastern Turkey. However, the findings are contrary to those of other researchers who reported higher prevalence in females than males [41]. Preponderance of male sero-positivity in this study may be due to the tendency of increased level of sexual activities among males than females reported in some studies in Nigeria [42]. Higher HBV sero-positive status in males can be attributed to the fact that males are less likely to clear HBV compared to females [42]. The reason for a higher frequency of $\mathrm{HBV} / \mathrm{HCV}$ co-infection among male patients could be a result of a higher level of exposure to risk factors associated with co-infection, including drug abuse, higher and unprotected sexual activities [43].

In our study, the levels of AST and ALT were significantly higher in HCV single infections than in HBV or both HBV and HCV participants. It has been reported that chronic hepatitis $\mathrm{C}$ is associated with variable ALT levels, ranging from normal to high and that persistently normal levels of ALT have been associated with a lower progression and occurrence of cirrhosis in patients with hepatitis [45]. This study however, disagreed with the work of [46], where higher levels of liver enzymes were reported in $\mathrm{HBV} / \mathrm{HCV}$ co-infected patients compared to those having HBV or HCV single-infection. The difference may be due to difference in geographical locations of the participants or possibly due to other comorbid conditions in the participants. 
Bilirubin was increased in $\mathrm{HBV}$ and $\mathrm{HCV}$ single infection than in both $\mathrm{HBV}$ and HCV dual infections; this study agreed with the study conducted in tribal populations of Central India which found an elevated level of bilirubin in $\mathrm{HBV} / \mathrm{HCV}$ co-infected patients [47] [48].

\section{Conclusions}

High prevalence of HBV, HCV and both $\mathrm{HBV}$ and $\mathrm{HCV}(51.8 \%, 32.6 \%$ and $15.6 \%)$ respectively was observed in this study. HBV and HCV seropositivity was found to be significantly high among 20 - 40 years while it was least among 41 60 years and above. Hepatitis B single seropositivity was highest, followed by hepatitis $\mathrm{C}$ single seropositivity while both $\mathrm{B}$ and $\mathrm{C}$ dual sero prevalence was the least among the seropositive participants in this study. Our study also showed that age group 20 - 40 years had $74.3 \%$ hepatitis B seropositivity, $76.1 \%$ hepatitis C seropositivity, while $85.7 \%$ had both hepatitis B and C seropositivity. Participants with age group $41-60$ years had $20.3 \%, 21.7 \%$ and $14.3 \%$ for hepatitis B, C and both B \& C seropositivity respectively

There was no significant difference between gender and liver function markers $(\mathrm{p}>0.05)$. There was no significant difference between hepatitis B and C seropositivity and liver function markers. However, the study showed significantly elevated AST and ALT liver function markers in hepatitis C seropositivity ( $p>$ 0.009). Consequently, this study updated data on serological epidemiology of hepatitis in the study facility. It also further affirms the need for at least AST and ALT as markers of liver function in all hepatitis suspected patients especially in poor resource setting where laboratory diagnostic capacities are not available or unaffordable for effective care and management of viral hepatitis.

\section{Conflicts of Interest}

The authors declare no conflicts of interest regarding the publication of this paper.

\section{References}

[1] Schweitzer, A., Horn, J., Mikolajczyk, R.T., Krause, G. and Ott, J.J. (2015) Estimations of Worldwide Prevalence of Chronic Hepatitis B Virus Infection: A Systematic Review of Data Published between 1965 and 2013. Lancet, 386, 1546-1555. https://doi.org/10.1016/S0140-6736(15)61412-X

[2] Radcke, S., Dillon, J.F. and Murray, A.L. (2015) A Systematic Review of the Prevalence of Mildly Abnormal Liver Function Tests and Associated Health Outcomes. European Journal of Gastroenterology \& Hepatology, 27, 1-7. https://doi.org/10.1097/MEG.0000000000000233

[3] Walana, W., Hokey, P. and Ahiaba, S. (2014) Sero-Prevalence of Hepatitis B Virus Infection among Blood Donors: A Retrospective Study in the Kintampo Municipal Hospital, Ghana. Open Journal of Medical Microbiology, 4, 64-69. https://doi.org/10.4236/ojmm.2014.41007

[4] Jombo, G.T., Egah, D.Z. and Banwat, E.B. (2005) Hepatitis B Virus Infection in a Rural Settlement of Northern Nigeria. Nigerian Journal of Medicine, 14, 425-428. 
https://doi.org/10.4314/njm.v14i4.37204

[5] Akani, C.I., Ojule, A.C., Opurum, H.C. and Ejilemele, A.A. (2005) Seroprevalence of Hepatitis B Surface Antigen HBs Ag in Pregnant Women in Port Harcourt Nigeria. Nigerian Postgraduate Medical Journal, 12, 266-270.

[6] Agbede, O.O., Iseniyi, J.O., Kolawole, M.O. and Ojuowa, A. (2007) Risk Factors and Seroprevalence of Hepatitis B Surface Antigenemia in Mothers and Their Preschool Age Children in Ilorin, Nigeria. Therapy, 4, 67-72.

[7] Harry, T.O., Bajani, M.D. and Moses, A.E. (1994) Hepatitis B Virus Infection among Blood Donors and Pregnant Women in Maiduguri Nigeria. East African Medical Journal, 71, 596-597.

[8] Jatau ED and Yabaya A. (2009) Sero Prevalence of Hepatitis B Virus in Pregnant Women Attending a Clinic in Zaria, Nigeria. Science World Journal, 4, 7-9. https://doi.org/10.4314/swj.v4i2.51837

[9] Nwokedi, E.E., Emokpae, M.A., Taura, A.A. and Dutse, A.I. (2006) The Trends of Hepatitis B Surface Antigenemia among Teaching Hospital Patients in Kano. African Journal of Clinical Experimental Microbiology, 7, 143-147.

https://doi.org/10.4314/ajcem.v7i3.7445

[10] Liu, Z. and Hou, J. (2006) Hepatitis B Virus (HBV) and Hepatitis C Virus (HCV) Dual Infection. International Journal of Medical Sciences, 3, 57-62.

https://doi.org/10.7150/ijms.3.57

[11] Gower, E., Estes, C., Blach, S., Razavi-Shearer, K. and Razavi, H. (2014) Global Epidemiology and Genotype Distribution of the Hepatitis C Virus Infection. Journal of Hepatology, 61, S45-S57. https://doi.org/10.1016/j.jhep.2014.07.027

[12] Konstantinou, D. and Deutsch, M. (2015) The Spectrum of HBV/HCV Coinfection: Epidemiology, Clinical Characteristics, Viralinteractions and Management. Annals of Gastroenterology: Quarterly Publication of the Hellenic Society of Gastroenterology, 28, 221-228.

[13] Donato, F., Boffetta, P. and Puoti, M. (1998) A Meta-Analysis of Epidemiological Studies on the Combined Effect of Hepatitis B and C Virus Infections in Causing Hepatocellular Carcinoma. International Journal of Cancer, 75, 347-354. https://doi.org/10.1002/(SICI)1097-0215(19980130)75:3\%3C347::AID-IJC4\%3E3.0. $\mathrm{CO} ; 2-2$

[14] Limdi, J.K. and Hyde, G.M. (2003) Evaluation of Abnormal Liver Function Tests. Postgraduate Medical Journal, 79, 307-312. https://doi.org/10.1136/pmj.79.932.307

[15] Khattak, A., Nawaz, H., Khan, J. and Khan, H. (2012) Frequency of Hepatitis B and C on Screening in Dera Ismail, Khan. Gomal Journal of Medical Sciences, 10, 84-86.

[16] Petersen, N.J., Barrett, D.H., Bond, W.W., Berquist, K.R., Favero, M.S., Bender, T.R., et al. (1976) Hepatitis B Surface Antigen in Saliva, Impetiginous Lesions, and the Environment in 2 Remote Alaskan Villages. Applied and Environmental Microbiology, 32, 572-574. https://doi.org/10.1128/aem.32.4.572-574.1976

[17] Shapiro, C.N. (1993) Epidemiology of Hepatitis B. The Pediatric Infectious Disease Journal, 12, 433-437. https://doi.org/10.1097/00006454-199305000-00036

[18] Global Advisory Committee on Vaccine Safety (GACVS) (2008) WHO Weekly Epidemiological Record. World Health Organization, Geneva.

[19] Stroffolini, T., Gaeta, G.B. and Mele, A. (2007) AASLD Practice Guidelines on Chronic Hepatitis B and HBV Infection in Italy. Hepatology, 46, 608-609. https://doi.org/10.1002/hep.21841

[20] Altiparmak, E., Koklu, S., Yalinkilic, M., Yuksel, O. and Cicek, B. (2005) Viral and 
Host Causes of Fatty Liver in Chronic Hepatitis B. World Journal of Gastroenterology, 11, 3056-3059. https://doi.org/10.3748/wjg.v11.i20.3056

[21] Sharma, R., Sharma, C.L. and Khajuria, R. (2004) The Knowledge, Attitude and Practices Regarding HBV Infection of Married Women in the Reproductive Age Group living in Cantonment Area, Sunjawan, Jammu. JK Science: Journal of Medical Education \&Research, 6, 127-130.

[22] McMahon, B.J. (2005) Epidemiology and Natural History of Hepatitis B. Seminars in Liver Disease, 25, 3-8. https://doi.org/10.1055/s-2005-915644

[23] Global Database on Blood Safety (2011) Summary Report 2011. World Health Organization, Geneva.

http://www.who.int/bloodsafety/global_database/GDBS_Summary_Report_2011.pd f?ua $=1$

[24] Nelson, P.K., Mathers, B.M., Cowie, B., Hagan, H., Des Jarlais, D., Horyniak, D., et al. (2011) Global Epidemiology of Hepatitis B and Hepatitis C in People Who Inject Drugs: Results of Systematic Reviews. Lancet, 378, 571-583.

https://doi.org/10.1016/S0140-6736(11)61097-0

[25] Thomas, D.L., Villano, S.A., Riester, K.A., Hershow, R., Mofenson, L.M., Landesman, S.H., et al. (1998) Perinatal Transmission of Hepatitis C Virus from Human Immunodeficiency Virus Type 1-Infected Mothers. Women and Infants Transmission Study. The Journal of Infectious Diseases, 177, 1480-1488.

https://doi.org/10.1086/515315

[26] Platt, L., Easterbrook, P., Gower, E., McDonald, B., Sabin, K., McGowan, C., et al. (2016) Prevalence and Burden of HCV Co-Infection in People Living with HIV: A Global Systematic Review and Meta-Analysis. Lancet Infectious Diseases, 16, 797-808. https://doi.org/10.1016/S1473-3099(15)00485-5

[27] Terrault, N.A., Dodge, J.L., Murphy, E.L., Tavis, J.E., Kiss, A., Levin, T.R., et al. (2013) Sexual Transmission of Hepatitis C Virus among Monogamous Heterosexual Couples: The HCV Partners Study. Hepatology, 57, 881-889. https://doi.org/10.1002/hep.26164

[28] Metwally, A., Mohsen, A., Saleh, R., Foaud, W., Ibrahim, N., Rabaah, T., et al. (2014) Prioritizing High-Risk Practices and Exploring New Emerging Ones Associated with Hepatitis C Virus Infection in Egypt. Iranian Journal of Public Health, 43, 1385-1394.

[29] Grebely, J., Page, K., Sacks-Davis, R., van der Loeff, M.S., Rice, T.M., Bruneau, J., et al. (2014) The Effects of Female Sex, Viral Genotype, and IL28B Genotype on Spontaneous Clearance of Acute Hepatitis C Virus Infection. Hepatology, 59, 109-120. https://doi.org/10.1002/hep.26639

[30] Thein, H.H., Yi, Q., Dore, G.J. and Krahn, M.D. (2008) Estimation of Stage-Specific Fibrosis Progression Rates in Chronic Hepatitis C Virus Infection: A Meta-Analysis and Meta-Regression. Hepatology, 48, 418-431. https://doi.org/10.1002/hep.22375

[31] El-Serag, H.B. and Rudolph, K.L. (2007) Hepatocellular Carcinoma: Epidemiology and Molecular Carcinogenesis. Gastroenterology, 132, 2557-2576. https://doi.org/10.1053/j.gastro.2007.04.061

[32] Zali, R., Mohammad, K. and Farhadi, A. (1996) Epidemiology of Hepatitis B in the Islamic Republic of Iran. Eastern Mediterranean Health Journal, 2, 290-298.

[33] Zampino, R., Boemio, A., Sagnelli, C., Alessio, L., Elio Adinolfi, L., Sagnelli, E. and Coppola, N. (2015) Hepatitis B Virus Burden in Developing Countries. World Journal of Gastroenterology, 21, 11941-11953. https://doi.org/10.3748/wjg.v21.i42.11941 
[34] Tungtrongchitr, R., Treeprasertsuk, S., Ei, N.N., Thepouyporn, A., Phonrat, B. and Huntrup, A. (2006) Serum Leptin Concentrations in Chronic Hepatitis. Journal of the Medical Association of Thailand, 89, 490-499.

[35] Ojo, D.A., Ogwu, R.S.A., Okerentugba, P.O. and Okonko, I.O. (2013) Prevalence of Hepatitis B Virus (HBV) Seropositivity in a Cohort of People Living with HIV and AIDS in Abeokuta, Ogunstate, Southwestern Nigeria. Nature and Science, 11, 36-40.

[36] Elduma, A.H. and Elgabar, H.E.A. (2015) Coinfection of Hepatitis B and C in Patients Infected with HIV in Sudan. American Journal of Research Communication, 3, 88-96.

[37] Sule, W.F., Okonko, I.O., Yunusa, I.P., Odu, N.N. and Frank Peterside, N. (2011) Hepatitis B Surface Antigen (HBsAg) and Risk Factors of Transmission among Patients Attending Hospital in Ankpa, Kogi State, Nigeria. Nature and Science, 9, 37-44.

[38] Udeze, A.O., Aliyu, A.S., Kolawole, O.M., Okonko, I.O., Sule, W.F. and Akanbi, K. (2012) Hepatitis Bsurface Antigenaemia and Risk Factors of Transmission among Apparently Healthy Students of University of Ilorin, Ilorin-Nigeria. Scientia Africana, 11, 1-8.

[39] Mohammed, Y., Sharif, A. and Dabo, N. (2015) Seroprevalence of HBsAg among Patients with Febrile Illnessess in Murtala Muhammad Specialist Hospital, Kano, Nigeria. Bayero Journal of Pure and Applied Sciences, 8, 19-23. https://doi.org/10.4314/bajopas.v8i1.4

[40] Mehmet, D., Meliksah, E., Serif, Y., Gunay, S., Tuncer, O. and Zeynep, S. (2005) Prevalence of Hepatitis B Infection in the Southeastern Region of Turkey: Comparison of Risk Factors for HBV Infection in Rural and Urban Areas. Japanese Journal of Infectious Diseases, 58, 15-19.

[41] Babalola, E.T., Ainabe, O.B. and Okonko, I.O. (2013) Confirmation of Hepatitis B Surface Antigen (HBsAg) among Selected Tertiary Institution Students in Ogun State, Nigeria. Nature and Science, 11, 107-113.

[42] Lawal, O.A., Bakarey, A.S., Uche, L.N., Udeze, A.O. and Okonko, I.O. (2009) Hepatitis B Virus Infection among Prospective Humanimmuno Deficiency Virus Positive Blood Donors at Two Designated Blood Banks in Ibadan, Nigeria. World Applied Sciences Journal, 7, 1269-1274.

[43] Halim, M.D., Offor, E. and Ajayi, O.I. (1992) Epidemiologic Study of the Seroprevalence of Hepatitis B Surface Antigen and HIV-1 in Blood Donors. Nigerian Journal of Clinical Practice, 2, 45-55.

[44] Bini, E.J. and Perumalswami, P.V. (2010) Hepatitis B Virus Infection among American Patients with Chronic Hepatitis C Virus Infection: Prevalence, Racial/Ethnic Differences, and Viral Interactions. Hepatology, 51, 759-766.

https://doi.org/10.1002/hep.23461

[45] Woreta, T.A. and Alqahtani, S.A. (2014) Evaluation of Abnormal Liver Tests. Medical Clinics of North America, 98, 1-16. https://doi.org/10.1016/j.mcna.2013.09.005

[46] Wondimeneh, Y., Alem, M., Asfaw, F. and Belyhun, Y. (2013) HBV and HCV Seroprevalence and Their Correlation with CD4 Cells and Liver Enzymes among HIV Positive Individuals at University of Gondar Teaching Hospital, Northwest Ethiopia. Virology Journal, 10, Article No. 171. https://doi.org/10.1186/1743-422X-10-171

[47] Khunte, P., Khare, R.L., Beck, P. and Kumar, S. (2015) Prevalence of Hepatitis B Virus and Hepatitis C Virus Co-Infection in Human Immunodeficiency Virus Posi- 
tive Patients: A Study from Tribal Area of Central India. International Journal of Research in Medical Sciences, 3, 2311-2315.

https://doi.org/10.18203/2320-6012.ijrms20150622

[48] Ionita, G., Malviya, A., Rajbhandaric, R., William, W., Schluter, G., Sharmae, S., Kakchapatic, S., Rijalf, S. and Dixit, S. (2017) Seroprevalence of Hepatitis B Virus and Hepatitis C Virus Co-Infection among People Living with HIV/AIDS Visiting Antiretroviral Therapy Centres in Nepal: A First Nationally Representative Study. International Journal of Infectious Diseases, 60, 64-69.

https://doi.org/10.1016/j.ijid.2017.04.011

\section{List of Abbreviations}

HBV-Hepatitis B Virus, HCV-Hepatitis C Virus, HIV-Human Immuno deficiency virus, ALP-Alkaline Phosphatase, ALT-Transaminase Alanine, AST-Transaminase Aspartate, CLD-Chronic Liver Disease. 